EXEMPLARIa Classica

Journal of Classical Philology

16, 2012, pp. 17-34

ISSN 1699-3225

\title{
LUCES Y SOMBRAS EN LA COMUNICACIÓN CON APOLO, DE LA MONODIA DE IÓN A LA DE CREÚSA
}

\author{
José Antonio Fernández Delgado \\ Universidad de Salamanca \\ jafdelgado@usal.es
}

\section{SUMMARY}

The present work aims to analyze the contrast, as far as the characterization of Apollo is concerned, between the two monodies with which the Ion of Euripides respectively opens and to some extent closes, the former placed in the mouth of the young protagonist and the second delivered by his august mother. The conclusion is that the intertextual play between these two peculiar examples of the hymnic genre contributes to smoothing their most exacerbated features, providing a conciliatory solution to the god's role.

KEYWORDS

Apollo, Ion, intertextuality / intratextuality, monody, hymn

\section{RESUMEN}

El presente trabajo se propone analizar el contraste existente, en lo que al tratamiento de la figura de Apolo se refiere, entre las dos monodias con que respectivamente se abre y en cierta medida se cierra el Ión de Eurípides, la una puesta en boca del joven protagonista y la otra pronunciada por su augusta madre. La conclusión es que el juego intertextual entre tan peculiares exponentes del género hímnico contribuye a limar sus rasgos más exacerbados para una solución conciliatoria del papel de la divinidad.

PaLABRAs Clave

Apolo, Ión, Intertextualidad / intratextualidad, monodia, himno

Fecha de recepción: 12/8/2012

Fecha de aceptación y versión final: 18/10/2012

1. En un trabajo presentado en las anteriores Jornadas de Filología Clásica de las Universidades de Castilla y León he tratado de la versión, menos brillante y olímpica, que algunas fuentes literarias ofrecen de la divinidad délfica frente a su noble imagen oficial ${ }^{1}$. Entre esas fuentes destacaba el indigno papel

${ }^{1}$ J. A. Fernández Delgado, "La otra cara de Delfos", en M. A. Sánchez Manzano (ed.), Sabiduría simbólica y enigmática en la literatura grecolatina (Actas de las XXII Jornadas de Filología Clásica de las Universidades de Castilla y León, León 2009), Madrid 2011. El presente trabajo, por su parte, fue presentado en las XXIII Jornadas de Filología Clásica de las Universidades de Castilla y León, celebradas en Valladolid en 2010 con el título ; Que los dioses nos escuchen! Comunicación con lo divino en el mundo greco-latino y su pervivencia y 
adjudicado a Apolo en el Ión de Eurípides en contraposición a su imponente función en el Edipo Rey de Sófocles, al margen o no de una posible relación intertextual entre ambas tragedias. Pues bien, esa misma dicotomía sobre la figura de Apolo que la pieza euripidea parece establecer con respecto a la de Sófocles, puede observarse, en el microcosmos de la primera de dichas obras, entre las dos importantes monodias que la adornan, la monodia puesta en boca de Ión, con la cual arranca la obra tras el prólogo sirviendo de carta de presentación del protagonista (vv. 82-183), y la entonada por su madre, Creusa, al final del segundo tercio de la misma y que realmente constituye "el centro estructural y emotivo de la obra" (vv. 859-922)2, según intentaré hacer ver'.

No es de extrañar que la doble faceta de un Apolo que comunica la verdad a los mortales a través de su oráculo délfico, que es el aspecto de la divinidad más destacado en la monodia de Ión, alterne en la misma obra con la del vulgar violador de Creusa y abandonador de la criatura, de que le acusa ella en la suya, si se piensa que la indefinición de la función del dios constituye precisamente la cuestión de fondo de la pieza ${ }^{4}$. La crítica se plantea si el oscuro papel desempeñado por Apolo en esta responde a la influencia de las ideas antirreligiosas de la Sofística en Eurípides ${ }^{5}$ o si, por el contrario, el dios, que no llega a darse a ver en toda la obra, adopta un papel providente con respecto a la estirpe ateniense de Creusa, según al final se desprende de la intervención de su hermana Atenea como dea ex machina (vv. 1.553-605, 1.614-5) ${ }^{6}$. Por otro lado, el canto favorable a Apolo es puesto en boca de una criatura inocente, Ión, cuyo mundo se limita al formidable santuario délfico, en el que siempre ha vivido y del cual recibe su sustento; el canto acusatorio es entonado por la víctima, mujer y engañada por el dios y por su esposo, un tipo de personaje sin duda destinado a despertar la conmiseración de Eurípides ${ }^{7}$. Por lo demás, hay una serie de indicios que parecen apuntar a una relación intertextual, es decir, intratextual en este caso, entre ambas monodias, con lo cual ciertos

dedicadas como homenaje a la colega fallecida Carmen Barrigón; en el volumen de Actas, publicado en Valladolid en 2012, el trabajo no fue publicado por error involuntario de su coeditora.

${ }^{2}$ K. H. Lee, Euripides. Ion, Introd., Transl. and Commentary, Warminster 1997, 257.

${ }^{3}$ De gran ayuda para el trabajo han sido ciertas sugerencias puntuales del excelente comentario de Lee cit., ad loc. Cf. también S. E. Hoffer, "Violence, Culture, and the Workings of Ideology in Euripides' Ion", ClAnt 15.2, 1996, 289-318.

${ }^{4}$ Cf. J. L. Calvo Martínez, Eurípides. Tragedias II, Introd., trad. y notas, Madrid 1978, 144ss., con bibliografía.

${ }^{5}$ Cf. M. Ostwald, "Atheism and the Religiosity of Euripides”, en T. Breyfogle (ed.), Literary Imagination, Ancient and Modern, Chicago 1999, 33-49.

${ }^{6}$ Cf. G. Norcia, "Lo Ione di Euripide: ierogamia e autoctonia nell'intreccio drammatico", Sungraphe 2, 2000, 43-64.

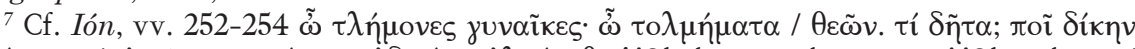

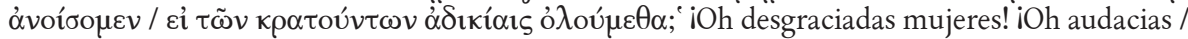
de los dioses! ¿Qué? ¿A dónde hemos de remitir la justicia / si somos víctimas de las injusticias de los que mandan?' 
rasgos aparentemente contradictorios de estas puede que se vean mutuamente matizados, ya sea en la segunda de las monodias a la luz de la primera, ya sea en la primera a la luz de la segunda, de acuerdo con la capacidad de repercusión, directa e inversa, característica del intertexto ${ }^{8}$.

2. De la mano, pues, de esos indicios que apoyan la conexión entre ambos textos, intentaré apreciar su grado de contraposición así como de complementariedad en la configuración que ofrecen del dios y su comunicación con los fieles:

2.1. Algunos, más que indicios, son hechos, como el fundamental de que ambos textos tratan de Apolo (el primero en tercera persona, el segundo dirigiéndose a él), su ejecución se sitúa en el santuario délfico, en el exterior del templo, en ambos casos, los dos son puestos en boca de los dos personajes principales de la obra y los dos son monodias, un componente sumamente característico de la tragedia euripidea que él explotó sobremanera, hasta el punto de suscitar, cómo no, los sarcasmos de Aristófanes?.

La monodia de Ión consta de cuatro partes, la primera recitada y las otras tres cantadas; en la primera (vv. 82-111) pueden distinguirse dos secciones, de las cuales la primera (vv. 82-93) celebra la salida del sol y el nuevo día y describe el comienzo de la actividad del templo el día de consulta oracular (en el cual, no hay que olvidarlo, Creusa y Juto, los padres del niño perdido Ión, van a consultar el oráculo para tener descendencia); la segunda (vv. 94-111)

${ }^{8}$ Sobre los conceptos teóricos utilizados cf. el instructivo librito de N. Piégay-Gros, Introduction à l'Intertextualité, Paris 1996, y otra bibliografía en U. J. Hebel, Intertextuality, Allusion and Quotation. An International Bibiliography of Critical Studies, New York-London 1989; H. F. Plett (ed.), Intertextuality, Berlin-New York 1991; G. Hassler (ed.), Texte im Text. Untersuchungen zur Intertextualität und ihren sprachlichen Formen, München 1997. Sobre la aplicación de la teoría al campo de la filología clásica son importantes: G. D'Ippolito, L'approccio intertestuale alla poesia. Sondaggi da Vergilio e dalla poesia cristiana greca di Gregorio e di Sinesio (Quaderni dell Ist. di Filol. Greca della Univ. di Palermo, 14), Palermo 1985; G. B. Conte \& A. Barchiesi, "Imitazione e arte allusiva. Modi e funzioni dell'intertestualità", en G. Cavallo, P. Fedeli e A. Giardina (eds.), Lo spazio letterario di Roma Antica, I: La produzione del testo, Roma 1989, 81-114; M. G. Bonanno, L'allusione necessaria. Ricerche intertestuali sulla poesia greca e latina, Roma 1990; L. Edmunds, "Intertextuality today", en V. Citti (ed.), Atti del Convegno Internazionale "Intertestualità: il "dialogo" fra testi nelle letterature classiche" (Cagliari, 24-26 novembre 1994) = Lexis 13, 1995, 3-22; D. Fowler, "On the Shoulders of Giants: Intertextuality and Classical Studies", MD 39, 1997, 13-34; S. Hinds, Allusion and Intertext. Dynamics of Appropriation in Roman Poetry, Cambridge 1998; V. Bécares, F. Pordomingo, R. Cortés Tovar \& J. C. Fernández Corte, Intertextualidad en las literaturas griega y latina, Madrid-Salamanca 2000. Aplicaciones de la teoría concretamente al campo de la comedia antigua son: N. V. Slater \& B. Zimmermann (eds.), Intertextualität in der griechisch-römischen Komödie, Stuttgart 1993; M. Quijada, "El festival de Dioniso: un marco propicio para la intertextualidad", en B. Bécares, F. Pordomingo, R. Cortés Tovar \& J. C. Fernández Corte, Intertextualidad, 41-57; L. Pérez Gómez, "Las voces y los ecos: palimpsesto y collage en el Amphitruo de Plauto", en V. Bécares, F. Pordomingo, R. Cortés Tovar \& J. C. Fernández Corte, Intertextualidad, 175-95.

${ }^{9}$ Ra. 944, 1.331-1.363. 
insta, por un lado, a los servidores del templo a purificarse antes de entrar y a mantener su boca apta para comunicar las respuestas a los consultantes, y por otro lado expone las tareas que, como cada día, él mismo se dispone a realizar, barrer la entrada del templo, regar el suelo y ahuyentar los pájaros que dañan las ofrendas, tareas que serán luego respectivamente desarrolladas en las otras tres partes que siguen, cantadas y de las cuales la primera (vv. 112-43) consta de un par estrófico que celebra a la escoba de barrer, la segunda y con mucho la más breve (vv. 144-53) es un ástrofon que atiende al riego y la tercera y última de la monodia (vv. 154-83) se aplica con detalle a la acción de espantar las aves.

La monodia de Creusa se compone de dos partes. En la primera (vv. 85961), tras una introducción cantada en tres versos en la que en forma de interrogaciones retóricas a sí misma se pregunta cómo hacer pública su violación, ya en forma recitada pasan estas a justificar su decisión seguidas de otros argumentos enunciativos sobre su desgraciada situación personal; en una segunda sección de esta primera parte (vv. 870-80) la heroína jura tres veces que va a descubrir el hecho y librarse así de los males que la acongojan. La segunda parte (vv. 881-922) es un canto de denuesto a Apolo tan brutal como no sabemos de otro en la literatura griega y que distribuye su materia también en dos secciones, una (vv. 881-906) dedicada al dios patrono de la música y la otra (vv. 907-22) al dios tutelar del oráculo délfico.

2.2. Ambas monodias responden a un tipo común que es el altamente emotivo $^{10}$, un estallido de intenso gozo la de Ión y un desahogo de intensa rabia tras un largo y forzado silencio la de Creusa. Si bien la monodia de Ión es mucho más larga que la de Creusa (101 líneas frente a 63), ambas constan igualmente de parte recitativa y parte cantada, y el ritmo de que se compone una y otra parte en la monodia de Creusa, que es el anapéstico, de tipo lírico en los tres primeros versos del comienzo (859-61) y en toda la segunda parte (vv. 881-92), de tipo recitativo en el resto de la primera parte, es el mismo que conforma también la parte primera de la monodia de Ión (vv. 82-111), a base de anapestos recitativos y más regulares, así como los anapestos del canto astrófico que constituye su tercera y última parte (vv. 144-83) ${ }^{11}$. La monodia de Ión, a su vez, contiene una parte central (vv. 112-43) compuesta de un par estrófico a base de metros eolios clausurados por yambos más un estribillo en metros molosos siguiendo a la estrofa y la antístrofa ${ }^{12}$.

${ }^{10}$ Cf. K. H. Lee, Euripides. Ion, 168, 258; W. Barner, "Die Monodie”, en W. Jens (ed.), Die Bauformen der griechischen Tragödie, München 1971, 277-320.

${ }^{11}$ Cf. K. H. Lee, Euripides. Ion, 168s., 257; M. L. West, Greek Metre, Oxford 1982, 94ss., 122ss. Cada una de las cuatro secciones que pueden distinguirse en el recitativo de Ión son delimitadas al final por un paremíaco: v. 88 (nuevo día), 92 (actividad en el templo), 101 (instrucciones a los servidores de templo), 111 (tareas propias); y los anapestos de la tercera parte, la que refiere el riego y que, aunque más breve, considero, a diferencia de K. H. Lee, Euripides. Ion, 171, que debe distinguirse de la cuarta, así como los de la cuarta parte, tienen un ritmo más libre y más espondaico.

${ }^{12}$ Cf. K. H. Lee, Euripides. Ion, 171s.; M. L. West, Greek Metre, 115ss. 
2.3. Desde el punto de vista estructural de ambas monodias el par estrófico de la de Ión tiene asimismo su componente homólogo en la parte cantada de la de Creusa por una razón tan particular que es difícil no ver en ella una motivación intratextual ${ }^{13}$. En ambos casos el esquema composicional característico del género hímnico, de tan amplia tradición en la literatura y en el culto religioso de los griegos, con su invocación, sus epítetos ornantes, sus oraciones de relativo o de participio describiendo una actitud típica del ensalzado $^{14}$, es utilizado aquí de manera inesperada. En la estrofa (vv. 112-23) Ión dedica su canto a un objeto tan poco noble (y en este sentido anticipativo, como el propio niño protagonista y otros rasgos de la obra, del juguetón y gracioso arte helenístico ${ }^{15}$ cual es la escoba, formada, eso sí, por una apolínea rama de laurel y follaje de mirto, y con la cual el muchacho barre cada día el suelo del altar délfico. La antístrofa (vv.128-40), sin duda el cénit estructural del total de esta oda a la alegría de cumplir diariamente con el servicio asignado en el santuario de Apolo, contiene una loa de Ión a su labor, que en su ánimo va más allá de la mera limpieza, que es reiterada a intervalos regulares

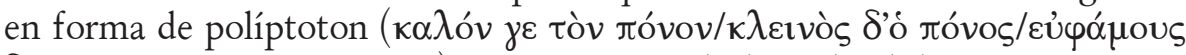

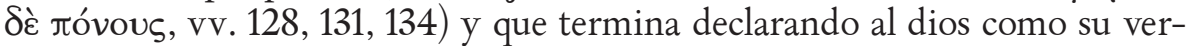
dadero padre, no porque realmente lo tenga por tal (cf. v. 109), sino, cuestión de eironeia trágica no exenta de ironía de la otra, porque de él vive ${ }^{16}$ : Фoĩßós

13 "Agramaticalidad" es término empleado por la teoría de la intertextualidad para designar un hecho textual que se sale de la norma y que por lo tanto permite ser claramente identificado, cf. M. Riffaterre, "L'intertexte inconnu", Littérature 41, 1981, 4-7. M. S. Mirto, Euripide. Ione, Intr., Trad., Commento, Milano 2009, 288 habla de simetría entre ambas monodias.

${ }^{14}$ Sobre los elementos constitutivos del himno son fundamentales: E. Norden, Agnostos Theos, Leipzig 1932; R. Wünsch, "Hymnos", RE IX 1, cols. 140ss.; K. Keyssner, Gottesvorstellung und Lebensauffassung im griechischen Hymnos, Stuttgart 1932, 1-8; cf. además K. Traede, "Hymnus I", Reallexikon für Antike und Christentum XV, Lief 126, Stuttgart 1993, cols. 915-46; W. D. Furley, "Praise and Persuasion in Greek Hymns", JHS 115, 1995, 29-46 y W. Horn, Gebet und Gebetsparödie in den Komödien des Aristophanes, Nuremberg 1970. Sobre la presencia del himno en Eurípides cf. W. D. Furley, "Hymns in Euripidean Tragedy", ICS 24-25, 1999-2000, 183-97.

${ }^{15}$ Cf. B. M. W. Knox, "Euripidean Comedy", en Word and Action. Essays on the Ancient Theater, Baltimore-London 1979, 250-274; K. Matthiessen, "Der Ion, eine Komödie des Euripides?", SEJG 31, 1989-1990, 271-291; M. Quijada Sagredo, "El elaborado tratamiento narrativo del Ión de Eurípides: ¿final de una época?”, en J. M. Nieto Ibáñez (ed.), Homenaje a G. Morocho Gayo, León 2003, 375-85; J. L. Calvo Martínez, "El otro Eurípides: melodramas y tragicomedias", FlorIlib 14, 2003, 35-51.

${ }_{16}$ Del mismo modo que en el mandato de Ión a los servidores del templo (sin duda los llamados prophetai, que daban forma inteligible a los balbuceos de la Pitia, cf. J. A. Fernández Delgado, "El testimonio de Plutarco y los nuevos estudios sobre los oráculos de Delfos", en Homenaje al Prof. A. Holgado, Cáceres 1991, 51-64) a purificarse para dar propicia respuesta a las consultas (vv. 94-101) cabe imaginar un efecto irónico en los espectadores, que saben ya que ese día los padres de Ión van a consultar sobre su descendencia, en todas estas reiteradas atenciones rituales de Ión para con el templo y el dios que le alimenta, incluido el desvío de los pájaros para que no dañen las ofrendas y las áureas construcciones, parece poder advertirse una fina alusión euripidea a las riquezas del santuario délfico, tradicional objeto de crítica (cf. J. A. 


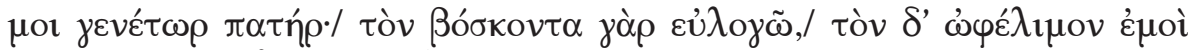

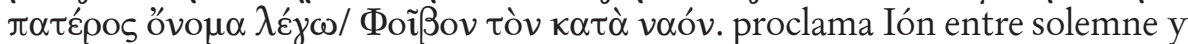
candoroso estómago agradecido, en forma de quiasmo, con anáfora de sus dos términos externos (Фoĩ $\left.\beta_{0}-\right)$ y reiteración de sus dos construcciones internas

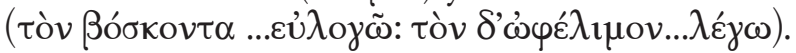

Reiteraciones aparte, y aparte también del estribillo de peán -el canto a Apolo por excelencia- que sigue a estrofa y a antístrofa, en lugares tan marcados como el final (v. 123) y el comienzo (v. 129-30) respectivamente de estas así como al final de cada una de las otras tres secciones que componen la monodia (vv. 110-1, 151-2, 181-3) encontramos sendas referencias al servicio a Apolo por parte de Ión, algunas mencionando también su sustento por parte del templo, lo suficientemente formularias como para sugerir de igual modo lo que aquella tiene de ritual, al margen de la sinceridad de los sentimientos del muchacho ${ }^{17}$. Los términos implicados son: de nuevo el epíteto Фoĩßos, los verbos $\lambda \alpha \tau \rho \varepsilon v ́ \omega / \theta \varepsilon \rho \alpha \pi \varepsilon v ́ \omega / \delta o v \lambda \varepsilon u ́ \omega$ (que recuerdan la denominación de los diferentes grados de culto -latría, dulía e hiperdulía- de nuestra religión) y eventualmente los participios $\theta \rho \varepsilon ́ \psi \alpha \nu \tau \alpha \varsigma / \beta o ́ \sigma \kappa o v \tau \alpha(\varsigma)$ en aposición a la sede apolínea.

En la segunda parte, de las dos en que se divide la monodia de Creusa, la introducción más la sección recitada y la sección cantada, esta (vv. 881-922) se sirve de la estructura de un himno en toda regla no para alabar, sino para lo contrario, reprochar la desleal conducta de la divinidad interpelada, que no es otra que el mismo Apolo. Al término que indica el sonido de la cítara

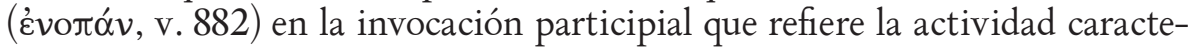
rística del dios, significativamente elegida en este caso y que adquiere ya algo de ominoso a través del epíteto óuv́xors (v. 883) "sin vida" que describe el material de que está hecho el mástil del instrumento musical ${ }^{18}$, Creusa contrapone el término asonante pero de sentido bien opuesto $\mu$ o $\mu \varphi^{\alpha} \nu$ (v. 885),

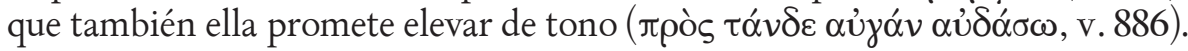

La sección que en la estructura del himno corresponde a la llamada pars epica o parte narrativa es reproducida aquí por el relato de la violación de Creusa por Apolo y el aciago final del hijo de ambos, ocupando uno y otro la misma extensión de diez versos (887-96: 897-906). La escena de la violación evoca el encuentro entre el dios "de áureos cabellos" y la joven cuando esta se hallaba recogiendo flores de azafrán para teñir sus vestidos -según el cuadro

Fernández Delgado, "Orakel-Parodie, mündliche Dichtung und Literatur im homerischen Hermes-Hymnus”, en W. Kullmann \& M. Reichel (eds.), Der Übergang von der Mündlichkeit zur Literatur bei den Griechen, Tübingen 1990, 199-225, 206ss. y E. IT v. 1275), y a un aspecto proverbial de su clero que era la voracidad, según reza un refrán (App. Prov. I 95: CPG Leutsch-Schneidewin) recogido por Plutarco, Quaest. Conv. VII 6 (Mor. 709A), $\Delta \varepsilon \lambda$ بoĩ

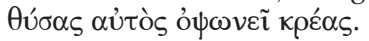

${ }^{17}$ Cf. K. H. Lee, Euripides. Ion, 171.

${ }^{18}$ Cf. M. S. Mirto, Euripide. Ione, 229. 
de género que ha hecho célebre el rapto de Perséfone por Hades en el himno homérico a Deméter- y su conducción a una oscura cueva mientras ella gritaba por su madre y él daba gusto a Afrodita con su desvergüenza, es decir, en términos cuya concesión al lenguaje poético del encuentro erótico y al poder de seducción del dios, a la escenografía mítica y tópica, si bien no evita el contraste entre la áurea figura de Apolo y su deplorable acción subsiguiente, quita algo de hierro a la brutalidad de la escena y de algún modo prepara para la revelación final de la obra, sobre la acción providente del dios ${ }^{19}$. En

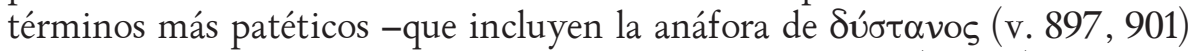

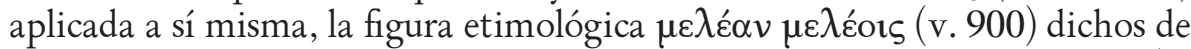
ella misma y del lecho de su violación o la trágica exclamación ớ $\mu \mathrm{or} \mu \mathrm{o}$ (v. 902) - es referido por Creusa su abandono del niño recién nacido, por miedo a su madre, en la misma yacija en que el dios la forzó, y la desaparición de la criatura pasto de las aves, mientras su padre "se dedica a tocar la cítara y cantar el peán” (v. 905-6), echa en cara Creusa al dios, recogiendo anularmente los términos utilizados en su invocación.

Anular y paralela con respecto a la del final de la invocación hímnica (vv. 886-7) es también la nueva interpelación con que comienza la última sección del canto monódico de Creusa (vv. 907-22), con la diferencia de que esta sustituye el término évo á́v (v. 882), relativo a la música de la cítara, por el asonante ỏ $\mu \varphi \alpha ́ v$ (v. 908), que designa la voz del oráculo délfico como dominio de Apolo relevante para esta parte del psogos de Creusa, frente al del Apolo músico y frívolo de la primera parte. Para cerrar la responsiva asonancia entre las designaciones de la voz de Apolo y la voz de Creusa, el término correspondiente a $\mu$ o $\mu \varphi \alpha ́ v$ de la primera parte del reproche (v. 885)

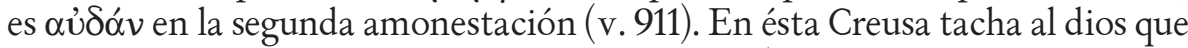

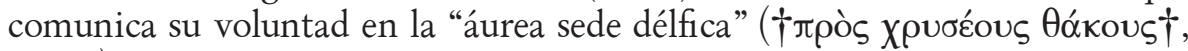
v. 910)-nueva concesión al lenguaje hímnico y nuevo contraste entre la simbología del oro y el inminente proceder de la divinidad ${ }^{20}$ - de amante desleal, ya que a su esposo Juto, al que nada tenía que agradecerle, le ha metido en casa al hijo que buscaba (por el cual había acudido al oráculo de Delfos y, en un típico equívoco mántico, entendió que Ión era ese hijo), mientras que el hijo de ambos ha perecido presa de las aves en sustitución de los pañales de su madre, dice Creusa (vv. 917-8) con sentida expresión. Tras la reiteración en parecidos términos y en forma de quiasmo del abandono del hijo de ambos y su devoramiento por las aves, en lugares homólogos del final de las dos secciones del canto ${ }^{21}$, la imprecación de Creusa al negligente músico y cantor divino

${ }^{19}$ Cf. F. M. Wassermann, “Divine Violence and Providence in Euripides' Ion”, TAPhA 71, 1940, 587-604; K. H. Lee, Euripides. Ion, 258; J. E. Thorburn, "Euripides' Ion: the Gold and the Darkness", CB 76.1, 2000, 39-49; D. J. Mastronarde, "Euripidean Tragedy and Theology", Seminari Romani di Cultura Greca 5, 2002, 17-49.

${ }^{20}$ Cf. J. E. Thorburn, "Euripides' Ion: the Gold and the Darkness".

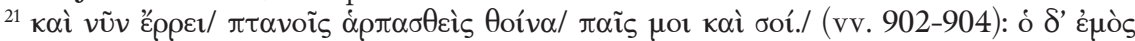


que en la anterior sección constituye la última frase (vv. 905-6) es sustituida aquí, como colofón de la monodia y buscando un marcado contraste con la actitud del dios y las circunstancias del parto de Creusa, por la proclamación del odio que por el dios siente Delos y el apolíneo laurel y la palmera donde en venerable parto le alumbró a él su madre Leto "en los jardines de Zeus" (vv. 919-22).

2.4. Algunos de los datos mencionados nos advierten de que la conexión textual entre el canto monódico de Creusa y el par estrófico de la monodia de Ión no se limita al sorprendente y desvirtuado uso en común de la estructura hímnica, aplicada a la escoba en el primer caso y a denigrar a la divinidad invocada en el segundo. Para empezar, los dos elementos de que consta el utensilio de limpieza, la rama de laurel y el mirto ${ }^{22}$, encuentran eco de su simbolismo, que es, respectivamente, la capacidad profética y la alternativa vinculación del mirto ya sea con Afrodita ya sea con Deméter y el más allá, el segundo en la violación de Creusa por Apolo (Kú $\pi \rho \imath \delta \imath$ Xó $\rho \imath v \pi \rho \alpha ́ \sigma \sigma \omega v$, v. 896) y la supuesta muerte de la criatura, y el primero en la referencia al oráculo délfico (vv. 908-910), de las dos secciones que componen el canto de vituperio de Creusa. La propia invocación a la rama de laurel, procedente

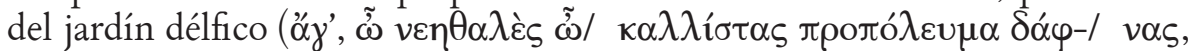

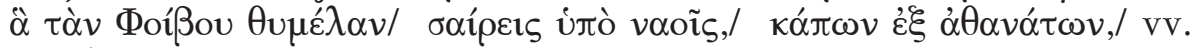
113-7), con que comienza la estrofa del canto de Ión, se convierte en sujeto de odio a Apolo cuando al final del canto de Creusa es mencionada como parte de la vegetación del "jardín de Zeus" en que aquel fue dado a luz en

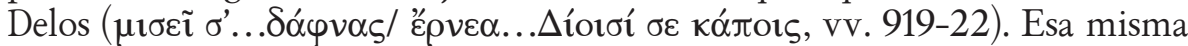
inversión en sentido negativo, del primero al segundo de los textos, de ciertas expresiones que se hallan presentes en ambos la encontramos en la propia invocación apolínea "hijo de Leto", la cual figura solamente dos veces en toda la monodia de Ión y en ambas en el estribillo congratulatorio que sigue a estrofa y antístrofa (v. $127=143)$, y otras dos veces en la monodia de Creusa, en la parte interpelativa de las dos secciones del canto (vv. 885, 907), pero aquí en el contexto del insulto (en combinación con el verbo $\alpha \dot{\delta} \delta \tilde{\omega}$ en ambos casos:

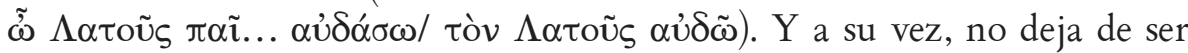
también una inversión de sentido, complementaria de la anterior aunque en este caso ex silentio, que el epíteto Febo (Фoîßos) de Apolo ("puro, brillante" según la etimología más comúnmente aceptada) ${ }^{23}$, comparezca nada menos que doce veces en el curso de la monodia de Ión y no esté presente ni una sola vez en la de Creusa, razón, entre otras, que hace que el título de la presente comunicación no sea una mera metáfora.

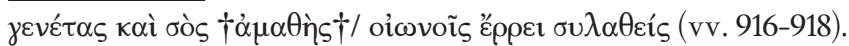

${ }^{22}$ Por lo que se ve no mero elemento ornamental, como piensa K. H. Lee, Euripides. Ion, comm. ad 120 .

${ }^{23}$ P. Chantraine, Dictionnaire Étymologique de la langue Grecque, Paris 1968, s.v. 
En la segunda interpelación insultante del canto de Creusa la sede oracular délfica es designada como ह̌ $\delta \rho \varsigma$ (v. 910), término utilizado con el mismo sentido en la laudatoria antístrofa del canto de Ión a su propio trabajo al servicio del dios (v. 130). En este mismo contexto Ión se jacta de que Febo es

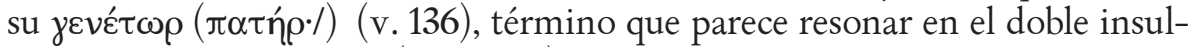

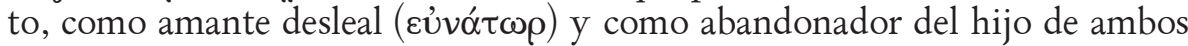

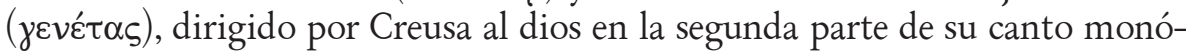
dico (vv. 912, 916). El primero de estos dos términos incluye a su vez otro, घủvó, que se repite en la primera parte de este canto, por separado (v. 899) y

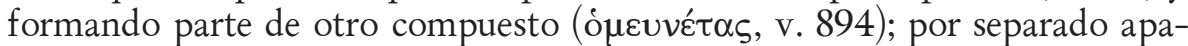
rece también en el tercero de los tres versos cantados que dan comienzo a la monodia de Creusa (Eủvós v. 861) y a través de sinónimos reitera el concepto

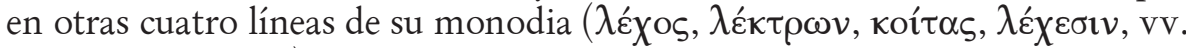
$874,880,892,900)$, concepto que pretende tener muy distinto significado al ser referido por Creusa, como en estos casos, al lugar de su violación por el dios y cuando en la sección que sigue a la antístrofa de la monodia de Ión es empleado por este, de forma "inopinadamente" irónica, para proclamar que

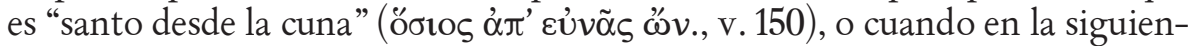
te y última parte de su canto sirve para formar un derivado que designa los

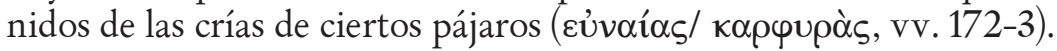

2.5. Si bien es entre la sección estrófica de la monodia de Ión y la parte cantada de la monodia de Creusa donde mejor se advierten las contraposiciones conceptuales en la configuración del dios, dentro del marco responsivo que les confiere su común estructura hímnica, aquellas no dejan de estar presentes en el resto de ambas composiciones, según acabo de señalar a propósito de ciertos términos. Así, el contraste entre el resplandor o la transparencia y la oscuridad, entre la luz y la sombra en suma, sugerido por la reiterada presencia del epíteto Фoĩßos en la monodia de Ión frente a su ausencia en la de Creusa, se manifiesta desde el comienzo mismo de ambas composiciones en el políptoton de la raíz $\lambda \alpha \alpha \mu \pi-$ "brillar" con que es celebrada por Ión la salida del sol en Delfos al inicio mismo de su monodia (vv. 1-7) ${ }^{24}$, frente

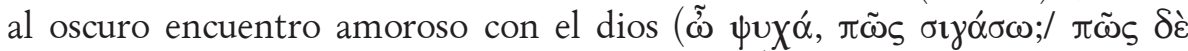

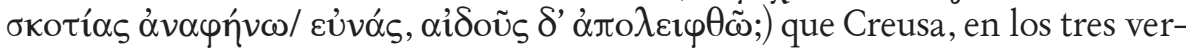
sos cantados que inician la suya, confiesa no acabar de atreverse a revelar tras silenciarlo todo el tiempo, aun cuando finalmente se decidirá a hacerlo públi-

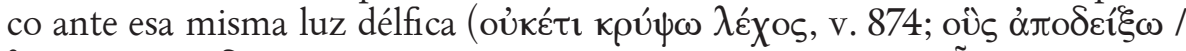

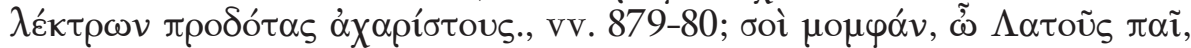

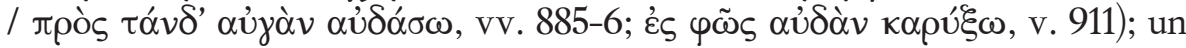
factor complementario de contraposición al respecto es la preeminencia de la luz del día sobre la noche, en la cual "se refugian las estrellas" (پ” $\sigma \tau \rho \alpha$, v. 84), al comienzo de la monodia de Ión, frente al juramento de Creusa "por la

${ }^{24} \Lambda \alpha \mu \pi \rho \grave{\alpha}$, v. $1 ; \lambda \dot{\alpha} \mu \pi \varepsilon 1$, v. $2 ; \kappa \alpha \tau \alpha \lambda \alpha \mu \pi \hat{\mu} \mu \varepsilon v \alpha 1$, v. 6. 


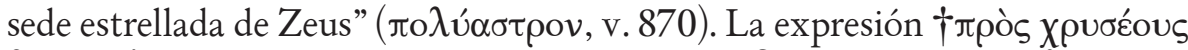

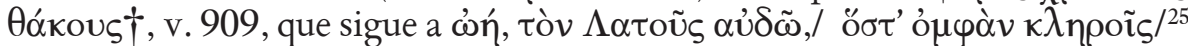
en la segunda interpelación del canto de Creusa a Apolo, en la que como dios tutelar de la sede délfica le reprocha el haber concedido un hijo a su esposo mientras dejó al nacido del dios y ella ser pasto de las aves (v. 907ss.), tampoco puede desvincularse del segundo párrafo del recitativo de Ión, que describe

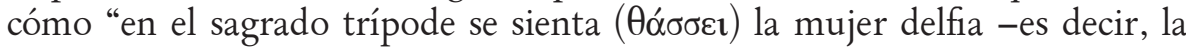
Pitia que, según consta ya en el prólogo de la obra, recogió al bebé Ión abandonado a las puertas del templo- cantando a los griegos las voces con que

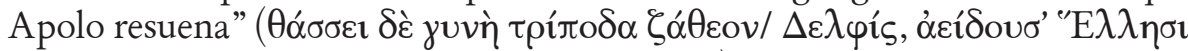

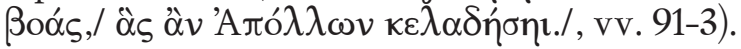

2.6. Un aspecto sumamente controvertido de la monodia de Ión es el que ocupa la última de las cuatro partes en que esta puede dividirse, a saber, el ástrofon anapéstico (vv. 154-83) que contiene, de acuerdo con el programa de tareas cotidianas fijado previamente (vv. 102-12), las amenazas con que el muchacho trata de espantar las aves que vienen a molestar al santuario, concretadas en el águila, el cisne y otro pájaro desconocido. De ellas, como

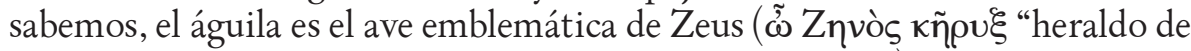
Zeus”, vv. 158-9, es el apelativo que en realidad le da Ión) y el cisne lo es de Apolo. Frente a los diversos intentos, a veces harto imaginativos, de explicar este inquietante componente de la composición ${ }^{26}$, creo que también su contemplación al reflejo intratextual de las referencias avícolas que tienen lugar en la monodia de Creusa puede arrojar luz sobre su significado, del mismo modo que la forma que aquí adoptan sirve para quitar hierro a su desabrida expresión en boca de la ultrajada heroína. De todos modos, la figura del sacerdote encargado de alejar los pájaros de los santuarios por los daños que causaban y el componente de impureza que comportaban no debió de ser infrecuente en el mundo griego y tiene su continuidad en el auceps o pajarero del mundo romano ${ }^{27}$.

El término empleado para referirse a los pájaros en general es el mismo en ambos pasajes ( $\pi \tau \alpha$ voì/ $\pi \tau \alpha$ voĩ, vv. 155/902, los dos situados al comienzo de sendos cola anapésticos de la misma medida y constituidos cada uno por tres términos del mismo volumen silábico y asonantes entre sí los homólogos: $\pi \tau \alpha v o i ̀ ~ \Pi \alpha \rho v \alpha \sigma o \tilde{~ k o i ́ \tau \alpha \varsigma / \pi \tau \alpha v o i ̃ s ~} \alpha \rho \pi \alpha \sigma \theta \varepsilon i \varsigma s \theta i ́ v \alpha)$, vocablo que posterior-

${ }^{25} \mathrm{La}$ expresión ỏ $\mu \varphi \grave{\alpha} v \kappa \lambda$ nрoĩ deriva de los orígenes clerománticos de la adivinación délfica e implícitamente describe las respuestas del oráculo (tal la que dio a Juto sobre Ión) como aleatorias, cf. M. S. Mirto, Euripide. Ione, 290.

${ }^{26}$ Cf. K. H. Lee, Euripides. Ion, 174; M. H. Giraud, "Les oiseaux dans l' Ion d'Euripide", $R P h$ 61, 1987, 83-94; A. K. Gavrilov, "Die delphischen Vögel im euripideischen Prolog (Eur. Ion 154-183”, Hyperboreus 1.1, 1994-1995, 92-112 M. S. Mirto, Euripide. Ione, 228ss., explicación más razonable.

${ }^{27}$ Cf. S. Montero, “La figura del auceps en el mundo romano: economía y religión”, Gerión 2007 (Vol. extra), 265-276. 
mente es variado en el primer caso por ópví $\theta \omega v(v v .159,171)$ y en el segundo por oicovoĩs (v. 917). Tras formular para todos ellos la prohibición (expresada mediante el mismo verbo, $\alpha \hat{\delta} \delta \tilde{\omega}$, v. 156, con que Creusa interpelará dos veces a Apolo en su canto monódico, vv. 887, 907, más otra vez con un nombre

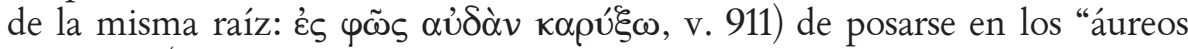

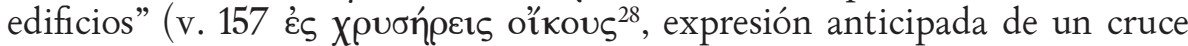

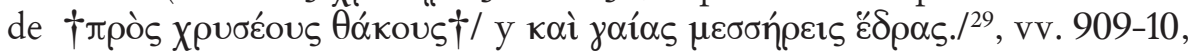

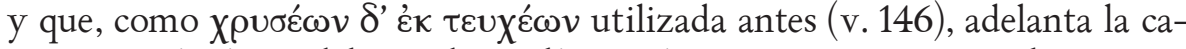
racterización áurea del mundo apolíneo irónicamente presente en la primera

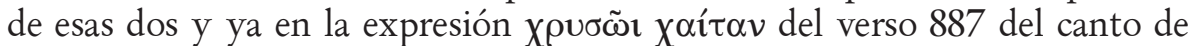
Creusa), la amenaza consiguiente es de darles muerte con su arco (el mismo

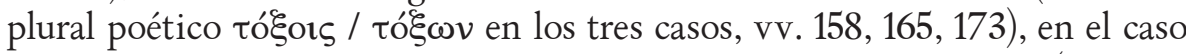
del águila de Zeus por más que "con su pico venza a las demás aves" (vv. 15960 ), en el caso del cisne "sin que de nada pueda servirle la canora fórminge de Febo...cuyos hermosos sones manchará de sangre" (vv. 164-5, 168-9 oủ ¿́vv

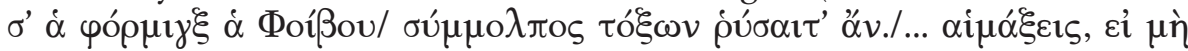

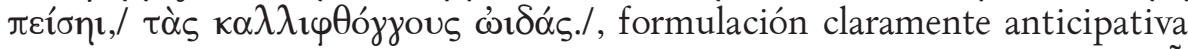
de la utilizada por Creusa para invocar a Apolo en su canto de denuesto, $\tilde{\omega}$

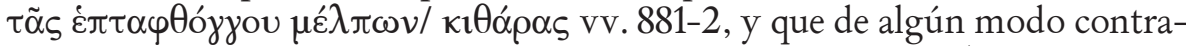
pone los dos símbolos característicos del dios: el arco y la lira ${ }^{30}$ ).

En el segundo caso y en el del pájaro desconocido, que sigue luego, la amenaza es acompañada de la conminación a marcharse, en el caso del cisne, al lago delio (v. 167), en el del pájaro ignoto a poner sus crías ( $\pi \alpha \imath \delta$ oúpye ${ }^{31}$, v. 175) en las corrientes del Alfeo o en la pradera del Istmo ("a fin de que no corrompan las ofrendas y templos de Febo", vv. 177-8), es decir, el cisne al otro gran santuario de Apolo (del que Creusa dirá que odia al dios, al final de su canto, v. 919), el otro pájaro a los célebres santuarios de Zeus en Olimpia o de Posidón en el Istmo de Corinto ${ }^{32}$ : creo que tal conminación no debe ser entendida, como lo es por parte de algún autor, en el sentido de una posible competencia entre Delfos y otros santuarios ${ }^{33}$, sino en el sentido de que, al igual que las dos primeras aves ahuyentadas por Ión pertenecen a los dos dioses más importantes del panteón griego (incluido el propio Apolo, al que él sirve), los lugares a los que ahuyenta las dos segundas están entre los san-

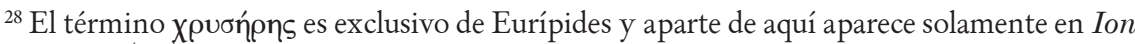
1154 e IT 129 (lír.). $16,1$.

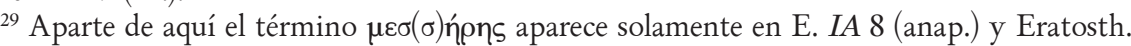

${ }^{30}$ Cf. M. S. Mirto, Euripide. Ione, 229.

${ }^{31}$ Hápax. La expresión juvì $\pi \alpha 1 \delta$ otoiòs, referida a una madre, aparece en Sófocles, $O T$ 1248.

${ }^{32}$ Cf. K. H. Lee, Euripides. Ion, 176.

${ }^{33}$ Cf. A. S. Owen, Euripides. Ion, Ed. with Introd. and Commentary, Oxford 1939, comm. ad 174-175. 
tuarios más importantes de Grecia aparte del délfico. En el caso del pájaro desconocido (al cual considero que no tiene mucho sentido tratar de identificar, como suele hacerse ${ }^{34}$, sino atender a lo que el poeta dice en relación con él), antes de proferir su amenaza Ión le pregunta "si es que se propone hacer el

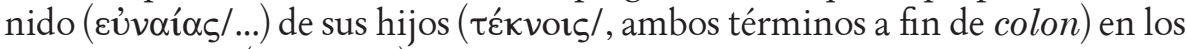
aleros délficos" (vv. 172-3), cosa que al impedir el muchacho viene a comportarse de un modo hasta cierto punto similar al de las aves que arrebataron a la criatura abandonada según el relato de Creusa y su propia terminología (vv.

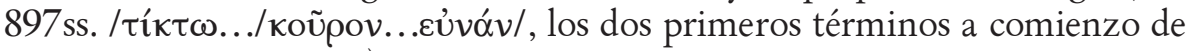
colon, el tercero al final). Ión termina su canto diciendo que "siente vergüenza $(\alpha i \delta o \tilde{v} \mu \alpha \mathrm{l} /)$ de matar las aves, mensajeras de los dioses, pero por encima de ello está el servicio a Febo y a quienes le dan de comer" (vv. 179-83); de igual modo Creusa introduce su monodia preguntándose a sí misma, alternativa y retóricamente, cantando en tres sonoros versos (859-61) con anáfora y asonancia de sus tres formas verbales en fin de verso, "cómo puede seguir callada o bien cómo va a revelar el secreto de su estupro y perder la vergüenza

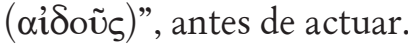

Con todo, el eco más significativo del episodio de los pájaros de la monodia de Ión en la monodia de Creusa es el que tiene lugar, de forma reiterativa y casi ritual y formularia (con lo que ello le resta de sentimiento), hacia el final de la primera interpelación a Apolo (como músico), tras el relato de la violación, el

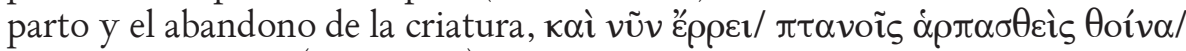

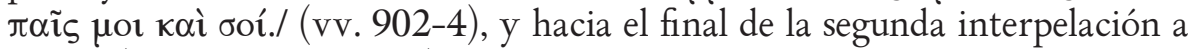
Apolo (como dios oracular), contraponiéndolo, trágica ironía, al destino de

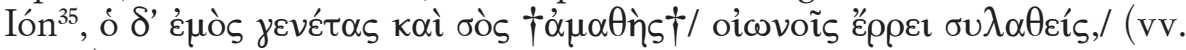
916-7). Al menos en este punto, cuando el espectador oye a Creusa reprochar a Apolo que el hijo de ambos ha desaparecido pasto de las aves, frente al hijo de su esposo, al que el dios va a establecer en su casa, no puede menos de haber pensado en la monodia de Ión y en su notable exposición del lugar en el que este se encuentra y cuáles son sus ocupaciones, una parte muy significativa de las cuales consiste precisamente en espantar, a tiros si hace falta, a los pájaros que merodean por el santuario délfico, empezando por alados tan importantes como el águila o el cisne; su primera referencia al asunto, en el compendio de tareas del final del recitativo que da comienzo a la monodia (vv. 106-8), contiene ya los elementos constitutivos de la coda señalada, solo que expresados

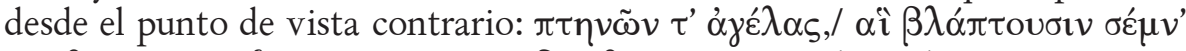

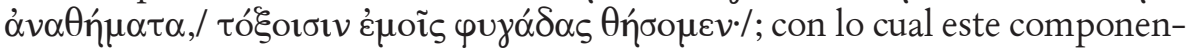
te de la acusación de Creusa a Apolo habrá sonado a los espectadores menos grave de lo que es y con ello restado también gravedad a la acusación misma,

${ }^{34}$ Cf. A. S. Owen, Euripides. Ion, comm. ad loc.

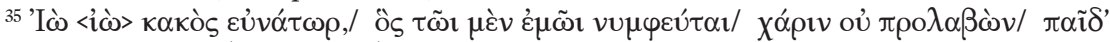

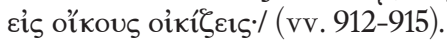


sirviendo así de estrategia preparatoria para el intento de exculpación final del dios providencial ${ }^{36}$.

3. Concluyendo, la influencia recíproca y el efecto intratextual de mutua modulación que tienen lugar entre dos estructuras composicionales en cierto sentido tan próximas como son las dos monodias del Ión, son sin duda el factor más importante de compatibilización en el seno de la misma obra de dos visiones tan dispares de la divinidad apolínea cuales son la transmitida por la gozosa monodia de su joven servidor Ión y la revelada por la amarga confesión de su víctima sexual la reina ateniense Creusa en su monodia. En virtud de la recíproca, aunque velada, aclaración y compensación que ambas composiciones ejercen entre sí, ni la primera resulta ser tan optimista, desinteresada y laudatoria ni la segunda tan crítica y desabrida con la figura del dios como a primera vista parecen. En todo caso una y otra concepción de Apolo y su forma de relacionarse con los fieles estaban ya en la tradición literaria griega desde sus comienzos; la originalidad y el golpe de audacia de Eurípides consistió en enfrentarlas dentro de la misma obra, aunque, eso sí, tomándose las cautelas necesarias para que la flagrante confrontación no impidiera al final, de la mano de la diosa patria Atenea como dea ex machina, una salida conciliatoria al conflicto.

${ }^{36}$ Cf. F. M. Wassermann, "Divine Violence and Providence in Euripides' Ion”, TAPhA 71; A. K. Gavrilov, “Apollons Orakelsprüch im Ion des Euripides (Dramaturgie, Theologie, Politik), Hyperboreus 8.1, 2002, 43-71. 
Apéndice Textual

Monodia de Ión (Ión, vv. 82-183)

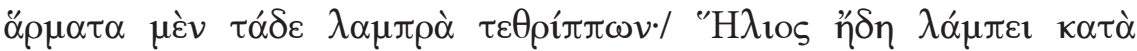

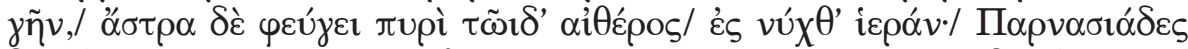

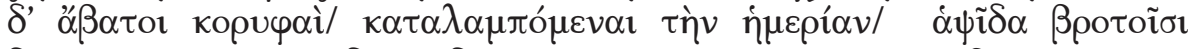

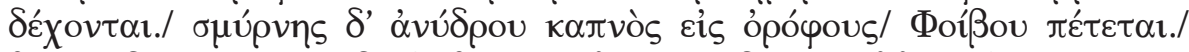

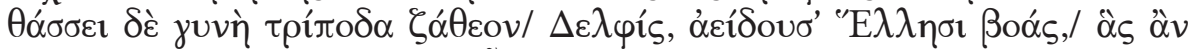

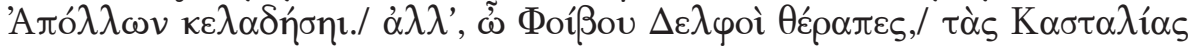

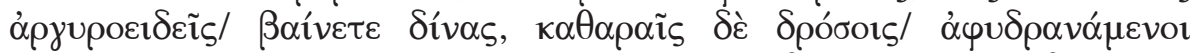

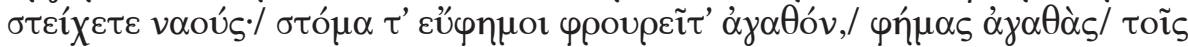

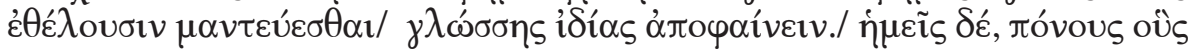

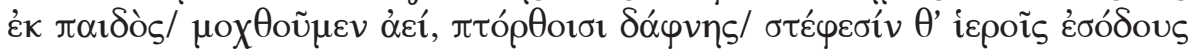

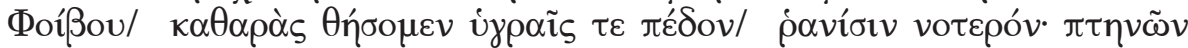

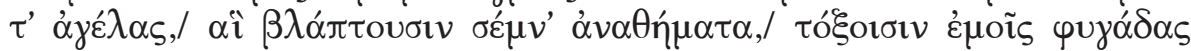

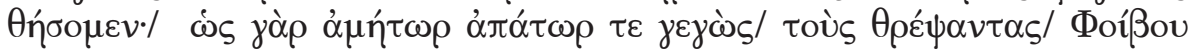
vooùs $\theta \varepsilon \rho \alpha \pi \varepsilon u ́ \omega . /$

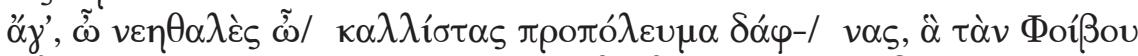

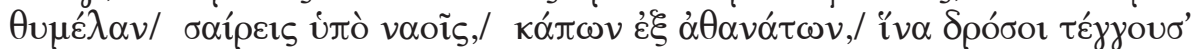

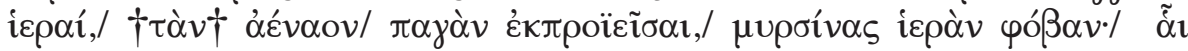

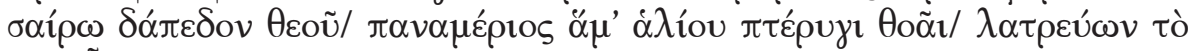
$\kappa \alpha \tau^{\prime} \tilde{\eta} \mu \alpha \rho . /$

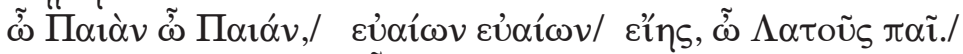

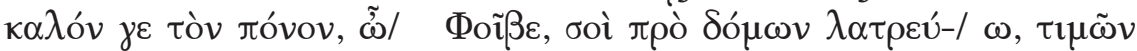

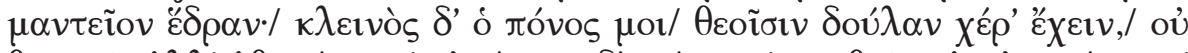

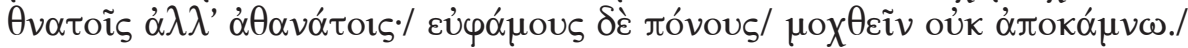

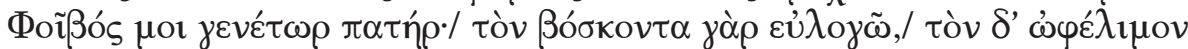

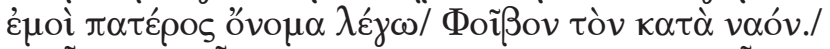

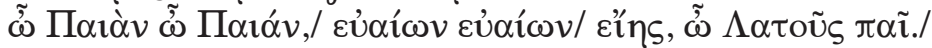

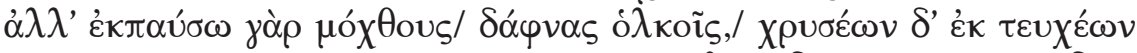

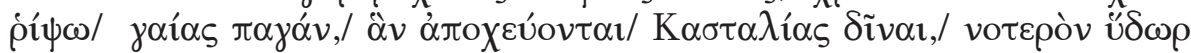

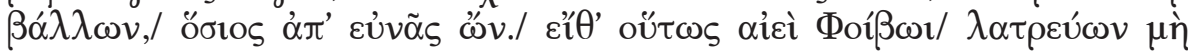

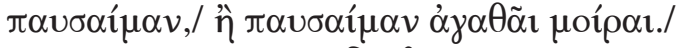

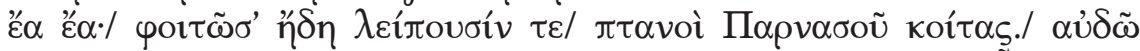

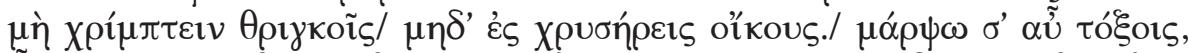

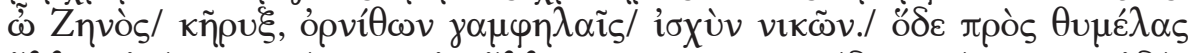

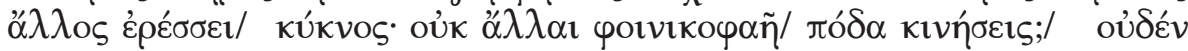

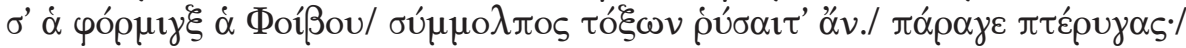

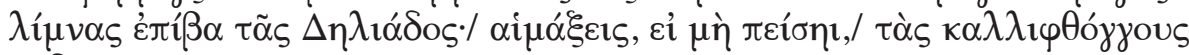

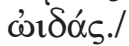

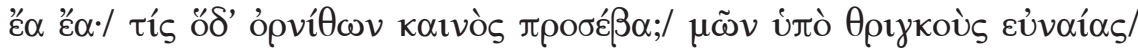

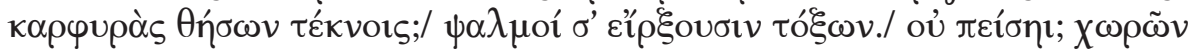

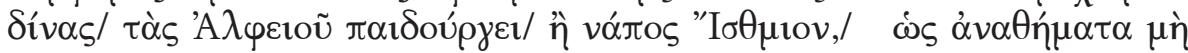




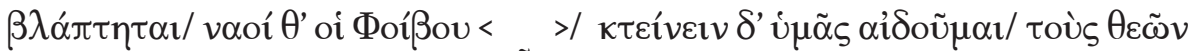

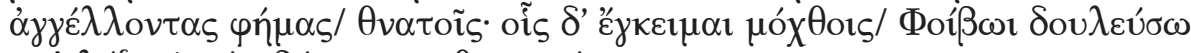

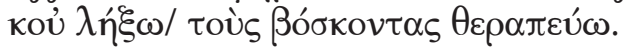

'He aquí los brillantes carros de cuadrigas; / Helio brilla ya sobre la tierra; / ante este fuego del éter las estrellas se refugian / en la noche sagrada / y las inaccesibles cumbres del Parnaso / reciben resplandecientes / el disco diurno para los mortales. / Humo de reseca mirra hasta los techos / de Febo se eleva / y en el muy divino trípode se sienta la mujer / delfia cantando para los griegos las voces / con que Apolo resuena. / Id, delfios servidores de Febo, / a las plateadas corrientes / de la fuente Castalia y entrad en el templo / rociados con sus puras aguas; / y mantened vuestra boca favorable y propicia / para dar buenas respuestas / con vuestra propia lengua / a quienes consultar el oráculo desean. / En cuanto a nos, los servicios que desde niño / prestamos constantemente, con ramas de laurel / y sagradas cintas dejaremos limpias / las entradas de Febo y con húmedas gotas / el suelo regado; y las bandadas de pájaros, / que dañan las augustas ofrendas, / con mi arco las pondremos en fuga; / pues, como nacido que soy sin madre y sin padre, / sirvo al templo de Febo, / que me ha criado.

Venga, utensilio / recién brotado del laurel más hermoso, / que el altar de Febo / barres al pie del templo, / procedente de inmortales huertos, / donde sagradas aguas proyectan / del suelo la sempiterna / fuente y empapan / del mirto el follaje sagrado; / con él barro el suelo del dios / todos los días, con la veloz ala del sol / haciendo el servicio diario.

Oh Peán, oh Peán, / bendito, bendito / seas, oh hijo de Leto.

Hermoso servicio, / Febo, presto ante tu morada / honrando la sede oracular; / glorioso servicio es para mí / ser mano de obra esclava de los dioses, / no mortales, sino inmortales; / servicios bienhadados / ejecutar no me cansa. / Febo es el padre que me engendró, / pues ensalzo al que me alimenta / y al que me es útil le doy el nombre de padre, / a Febo, que habita el templo.

Oh Peán, oh Peán, / bendito, bendito / seas, oh hijo de Leto.

Mas pondré fin a las tareas / de los meneos de laurel / y con áureos calderos arrojaré / el chorro de la tierra / que vierten / las corrientes de Castalia, / derramando líquida agua / como santo que soy desde la cuna. / Ojalá no cesara de servir / así siempre a Febo / o que cesara con buen sino. /

Eh, eh, / ya andan por aquí los pájaros / dejando sus nidos del Parnaso. / Ordeno que no os poséis en las cornisas / ni en los edificios cubiertos de oro. / A ti te alcanzaré con mi arco, heraldo / de Zeus, que vences con tu pico / la fuerza de las aves. / He aquí otro que rema hacia los altares, / un cisne: ¿no dirigirás a otra parte / tus rojizas patas? / Ni la fórminge de Febo, compañera / del canto y la danza, podrá protegerte de mi arco. / Aparta de aquí tus alas. / Ve a posarte a la laguna de Delos. / De sangre teñirás, si no obedeces, / el hermoso son de tus cantos. / Eh, eh, / iqué nueva ave es esta que se ha acer- 
cado? / ¿No irás a hacer bajo las cornisas / el nido de paja para tus hijos? / El chasquido de mi arco te lo impedirá. / ¿No vas a hacer caso? / Vete a criar / a las corrientes del Alfeo / o al soto del Istmo / para que no sufran daño las ofrendas / y los templos de Febo. / Me da vergüenza mataros, a vosotros / que anunciáis a los mortales / los mensajes de los dioses /, mas seré esclavo de Febo / en las tareas impuestas y no cesaré / de servir a quienes me alimentan'.

Monodia de Creusa (Ión, vv. 859-922):

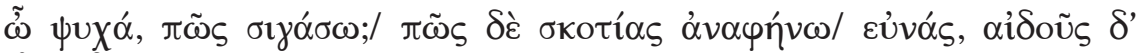
$\dot{\alpha} \pi \mathrm{o} \lambda \varepsilon i \varphi \theta \tilde{\omega} ; /$

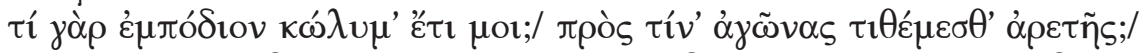

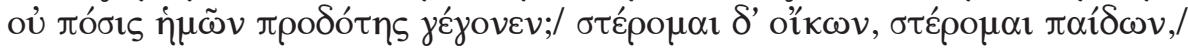

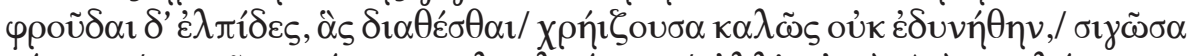

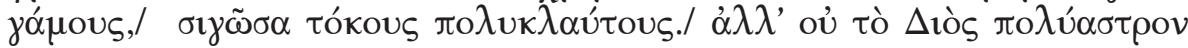

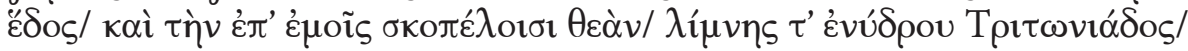

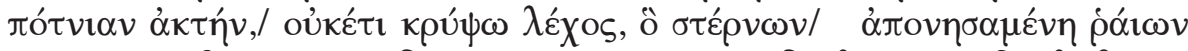

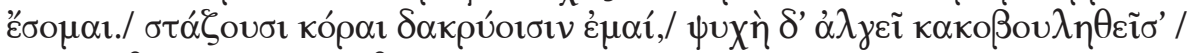

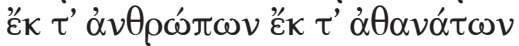

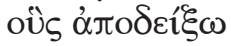

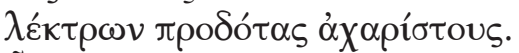

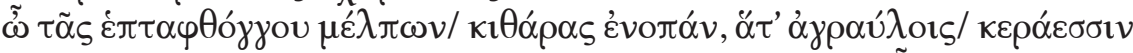

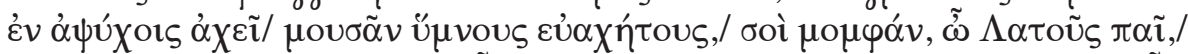

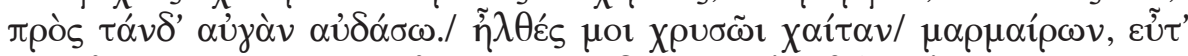

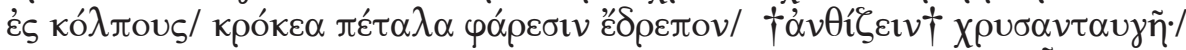

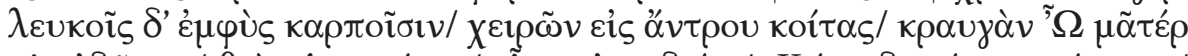

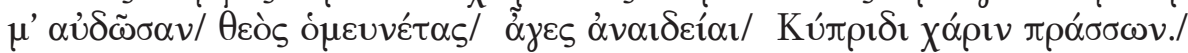

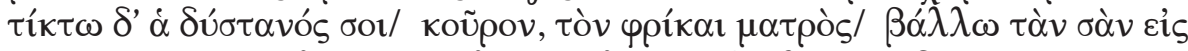

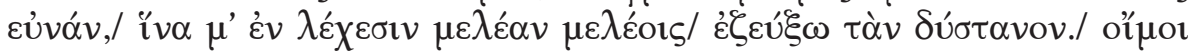

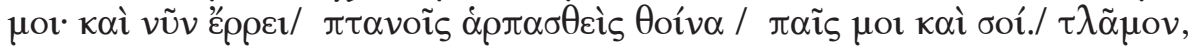

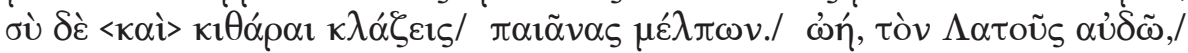

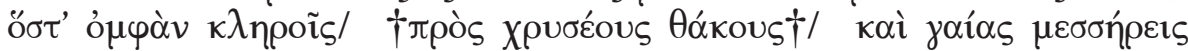

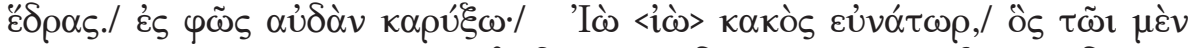

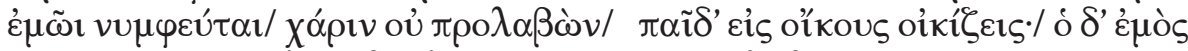

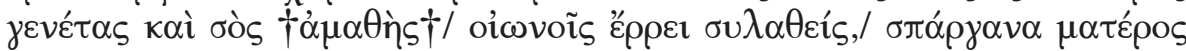

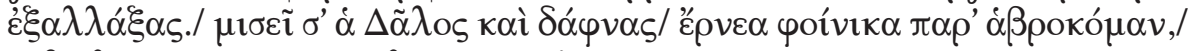

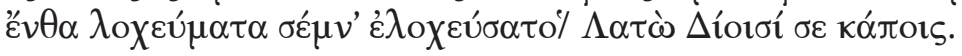

'Alma mía ¿cómo he de callarme? / y ¿cómo declarar mis oscuras / uniones y perder la vergüenza? / ¿Qué obstáculo hay ya, pues, que me lo impida? / ¿Contra quién estoy compitiendo en virtud? / ¿No ha resultado ser un traidor mi esposo? / Me quitan mi casa, me quitan a mis hijos, / se van mis esperanzas, que no pude cumplir / honrosamente cuando debía, / silenciando 
mis connubios, / silenciando los muy llorados partos. / Pero no, por la sede de Zeus muy estrellada, / por la diosa que reina en mis picos / y por la augusta ribera / del húmedo lago Tritónide, / ya no ocultaré más la unión amorosa: / estaré más a gusto / una vez que me quite esa carga del pecho. / Mis pupilas se inundan de lágrimas / y me duele el alma de ser maltratada / por humanos y por inmortales, / a los cuales pondré en evidencia / como desagradecidos traidores de mi lecho.

Oh tú que modulas la voz de la cítara / de siete tonos, la que en agrestes / cuernos exánimes hace sonar / los muy sonoros cantos de la música, / contra ti, oh hijo de Leto, / lanzaré mis reproches a la luz del día. / Viniste a mí refulgiendo de oro / en tu pelo cuando yo recogía / en mi regazo pétalos de crocus / para teñir de áureo brillo mis vestidos. / Me agarraste por mis blancas muñecas / y, por dar gusto a Cipris / con tu desvergüenza, me llevaste / a yacer a una gruta, / dios salteador de mi lecho, / mientras yo gritaba "madre". / Doy yo a luz, desgraciada, / a un muchacho tuyo, al que por temor a mi madre / arrojo en tu cama, / allí donde en aciagos lechos te uniste / a mí aciaga, desgraciada de mí. / Ay de mí, ay; y ahora se ha perdido, / arrebatado para festín de las aves, / mi hijo y el tuyo. Desgraciado, y tu [todavía] tocas la cítara / y cantas el peán. / Oh, eh, a ti te hablo, hijo de Leto, / que difundes la voz del oráculo / junto a los áureos asientos / y la sede central de la tierra. / Ante la luz del día alzo mi voz. / Oh, oh, amante malvado, / que a mi esposo / le das un hijo para habitar su casa / sin de él recibir favor, / y el nacido de mí y de ti, sin que lo supieras, / ha perecido presa de las aves, / que cambió por los pañales de su madre. / Delos te odia y los ramos / de laurel junto a la palmera de frondosa copa, / donde en augusto alumbramiento te alumbró / Leto en los jardines de Zeus.'

- El texto adoptado es el de J. Diggle, Euripidis Fabulae, Oxford 1981, con la salvedad de $\alpha i \mu \alpha ́ \xi \xi \varepsilon \varsigma$ (v. 168), que es recuperación de la lectura de los mss., en lugar de aió́geıs, conjetura de Nauck. Cf. M. S. Mirto, Euripide. Ione, ad loc. 
